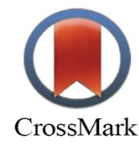

\title{
An Increased Level of Aryl Hydrocarbon Receptor in Patients with Pancreatic Cancer
}

\author{
Sahar Masoudi ${ }^{1}$, Amin Hassanzadeh Nemati ${ }^{2}$, Hamid Reza Fazli ${ }^{2}$, Samira Beygi ${ }^{2}$, \\ Maliheh Moradzadeh ${ }^{3}$, Akram Pourshams ${ }^{1}$, Ashraf Mohamadkhani ${ }^{2, *}$
}

\section{ABSTRACT}

1. Digestive Oncology Research Center, Digestive Disease Research Institute, Shariati Hospital, Tehran University of Medical Sciences, Tehran, Iran

2. Liver and Pancreatobiliary Diseases Research Center, Digestive Disease Research Institute, Shariati Hospital, Tehran University of Medical Sciences, Tehran, Iran

3. Golestan Rheumatology Research Center, Golestan University of Medical Sciences, Gorgan, Iran

\section{* Corresponding Author:}

Ashraf Mohamadkhani, PhD

Digestive Diseases Research Institute, Tehran University of Medical Sciences, Shariati Hospital, N. Kargar St., Tehran 14117, Iran

Tel: + 982182415227

Fax: + 982182415400

Email: mohamadkhani.ashraf@gmail.com

Received: 22 Mar. 2018

Accepted: 01 Oct. 2018

\section{BACKGROUND}

Aryl-carbon receptor (AhR), a ligand-activated transcription factor, is best known for its ability to mediate the effects of environmental toxins such as 2,3,7,8-tetrachlorodibenzo-p-dioxin. AhR is expressed in several tumor cells and regulates the expression of genes in the signal transduction pathways. In this study, we examined the soluble levels of AhR in patients with pancreatic cancer.

\section{METHODS}

123 samples, including $59(48 \%)$ samples of pancreatic ductal adenocarcinoma based on histological evidence and 64 (52\%) healthy control samples, were evaluated to determine plasma levels of AhR by Enzyme-linked immunoassay.

\section{RESULTS}

The median of AhR among patients was $0.280 \mathrm{ng} / \mathrm{mL}$, which differed considerably from 0.07 $\mathrm{ng} / \mathrm{mL}$ in the control group $(p<0.001)$. Significant differences of the AhR were observed between the plasma samples of the patients compared with the healthy group, with respect to male sex $(p<0.001)$, age groups $(p=0.001)$, diabetic status $(p<0.001)$, body mass index (BMI) categories $(p=0.035)$, and constantly smokers $(p<0.001)$. We also observed significant differences between the level of AhR expression between men and women $(p=0.01)$ and ever to never smokers $(p=0.009)$ in the case group. In addition, the age of 65 and a BMI of 25 or less were significant factors in plasma AhR levels ([1.61 95\%CI 1.08-2.38] and [1.84 95\%CI 1.22-2.77], respectively).

\section{CONCLUSION}

The results of this study can add diagnostic information to pancreatic cancer involving AhR and the potential efficacy of this receptor in therapeutic strategies.

\section{KEYWORDS:}

Pancreatic cancer, Aryl hydrocarbon receptor (AhR), Biomarkers

Please cite this paper as:

Masoudi S, Hassanzadeh Nemati A, Fazli HR, Beygi S, Moradzadeh M, Pourshams A, Mohamadkhani A. An Increased Level of Aryl Hydrocarbon Receptor in Patients with Pancreatic Cancer. Middle East J Dig Dis 2019;11:38-44. doi: 10.15171/mejdd.2018.126.

\section{INTRODUCTION}

The pancreatic ductal cell carcinoma is the fourth leading cause of cancer death worldwide. ${ }^{1,2}$ Despite many efforts, the causes of pancreatic cancer are unknown and the recognition of biomarkers helps in early diagnosis and treatment. ${ }^{3,4}$ Aryl hydrocarbon receptor (AhR) has been introduced as a regulator of carcinogenesis induced by xenobiotics. Recent data have shown that the knockdown of the AhR gene is associated with fewer proliferations and invasions of carcinogenic cell lines. AhR is interesting for its functional roles 
in mediating the toxicity of xenobiotic metabolism and cellular processes such as energy metabolism, immune function and tumorigenesis., ${ }^{5,6}$ It plays a role in the promotion and progression of tumors and may be present as a new target for pharmacological interference with cancer. ${ }^{6}$

AhR belongs to the basic subgroup helix-loop-helixPER-ARNT-SIM (bHLH-PAS) of the bHLH superfamily of transcription factors, which is phylogenetically conserved from invertebrates to vertebrates. Following binding to the ligand, AhR in the form of a cytoplasmic complex with co-chaperone is transferred into the nucleus and produces dimerism with the aryl hydrocarbon nuclear translocation (ARNT), ${ }^{7,8}$ This receptor was initially recognized for its high affinity by binding to the more toxic products and to the tumor promoter ligand of 2,3,7,8-tetrachlorodibenzo-p-dioxin (TCDD). ${ }^{5}$ However, various ligands from dietary compounds and endogenous synthetic materials (L-Kynurenine) and environmental chemicals are also involved in the activation of AhR. ${ }^{9}$ AhR is involved in the detoxification of environmental pollutants through binding to the sensitive xenobiotic element (XRE) in the promoters of the target genes. ${ }^{5,10}$ AhR activates genes that encode enzymes for the phase I drug, in which cytochrome P450 mono-oxygenases, dependent on cytochrome CYP1A1 and CYP1A2, are more important. ${ }^{11}$ The AhR also induces metabolic phase II enzymes, mainly transferase and glutathione peroxidase, and phase III enzymes related to conjugation and transport processes. ${ }^{9}$

These enzymes are related to adaptation between host and environment and expressed in many tissues, such as the liver, intestine, kidney, and brain and are also essential in the metabolism, elimination, and detoxification of xenobiotics introduced into the human body. ${ }^{10,12,13-15}$ In addition to drug metabolism, AhR plays an important role in modulating the activity of numerous signaling pathways and in regulating chronic inflammatory and immune processes. Furthermore, it was considered that AhR-mediated enzymes play a key role in tumor initiation processes following the transformation of lethal carcinogens into active genotoxins. ${ }^{7,16}$ The AhR is constitutively expressed with very different levels in the liver, lungs, spleen, heart, and kidneys, ${ }^{7,13}$ however it has been defined that AhR is highly upregulated in the lung, prostate, and pancreatic cancers. ${ }^{5,17}$ The increase in AhR levels in human tumors has approved the involvement of AhR at the beginning of the tumor progression and metastasis. ${ }^{6}$ However, few studies have thoroughly studied the level of AhR expression in pancreatic cancer. ${ }^{14}$

Despite the crucial role of AhR in human tumors and the exploration of AhR ligands in pharmaceuticals investigations, there are no reports of $\mathrm{AhR}$ expression in patients with pancreatic cancer. So in this study we determined the amount of circulating AhR in patients with pancreatic cancer compared with the healthy group and in association with their clinical features.

\section{MATERIALS AND METHODS}

\section{Patients}

Fifty nine consecutive patients with pancreatic cancer were enrolled at the Department of Gastroenterology, Shariati Hospital, Tehran, Iran. The patients were new incident cases with a histopathological diagnosis of adenocarcinoma and their tissues were achieved directly from the pancreas. ${ }^{18}$ Inclusion criterion of the patients was confirmed diagnosis of pancreatic cancer confined to the pancreas both histologically and clinically. In order to provide a matched control cohort, 64 individuals without cancer were included by a random sampling of a health examination cohort. Both cases and control subjects were recruited between the years 2012 and 2015. All individuals completed a valid and reliable questionnaire and venous blood samples from all the participants were collected in evacuated tubes containing EDTA anticoagulant. ${ }^{18}$ Plasma samples were prepared after centrifugation of blood samples and stored at $-70^{\circ} \mathrm{C}$ until tested according to certified procedures. ${ }^{19}$ The Ethics Committee of the Shariati Hospital, Tehran University of Medical Science, approved all procedures of this study.

\section{Quantification of AhR in the patients' plasma}

The patients' plasma levels of AhR were measured using an ELISA (enzyme-linked immunosorbent assay) kit (Abbexa Ltd., United Kingdom), following the manufacturer's instructions. Reproducibility were assessed by the intra-assay CV (\%) and inter-assay CV (\%). The linearity of the AhR assay has been demonstrated in the range of 0.05-4 ng/mL. The samples of patients containing more than the $4 \mathrm{ng} / \mathrm{mL}$ dose range were diluted with one or two parts of deionized water. The results were multiplied by the dilution factor. The sensitivity of the test was $0.01 \mathrm{ng} / \mathrm{mL}$. 
Table 1: Clinical features of 59 patients with pancreatic cancer compared with 64 healthy control

\begin{tabular}{|c|c|c|c|c|c|}
\hline Characteristics & & Case & Control & $P$ value & Total \\
\hline \multirow[t]{2}{*}{ Sex N (\%) } & Male & $29(49.2 \%)$ & $32(50 \%)$ & 1.00 & $61(49.6 \%)$ \\
\hline & Female & $30(50.8 \%)$ & $32(50 \%)$ & & $62(50.4 \%)$ \\
\hline \multirow[t]{2}{*}{ Age N $(\%)$} & $\leq 65$ years & $28(47.5 \%)$ & $32(50 \%)$ & 0.46 & $60(48.8 \%)$ \\
\hline & $>65$ years & $31(52.5 \%)$ & $32(50 \%)$ & & $63(51.2 \%)$ \\
\hline \multirow[t]{2}{*}{ Diabetes status N (\%) } & Yes & $18(30.5 \%)$ & $12(18.8 \%)$ & 0.09 & $30(24.4 \%)$ \\
\hline & No & $41(69.5 \%)$ & $52(81.3 \%)$ & & $93(75.6 \%)$ \\
\hline \multirow[t]{2}{*}{ Body mass index N (\%) } & $\leq 25 \mathrm{~kg} / \mathrm{m}^{2}$ & $38(64.4 \%)$ & $31(48.4 \%)$ & 0.05 & $69(56.1 \%)$ \\
\hline & $>25 \mathrm{~kg} / \mathrm{m}^{2}$ & $21(35.6 \%)$ & $33(51.6 \%)$ & & $54(43.9 \%)$ \\
\hline \multirow[t]{2}{*}{ Cigarette smoking N (\%) } & Ever & $40(67.8 \%)$ & $40(62.5 \%)$ & 0.33 & $80(65.0 \%)$ \\
\hline & Never & $19(32.2 \%)$ & $24(37.5 \%)$ & & $43(35.0 \%)$ \\
\hline
\end{tabular}

Table 2: Association between plasma level of AhR and baseline characteristics of all participants

\begin{tabular}{|c|c|c|c|c|}
\hline \multirow{2}{*}{ Characteristics } & & \multicolumn{3}{|c|}{$\operatorname{AhR}(\mathrm{ng} / \mathrm{mL})$} \\
\hline & & Mean \pm SD & Median & Pvalue \\
\hline \multirow[t]{2}{*}{ Sex N (\%) } & Male & $0.533 \pm 1.41$ & 0.100 & 0.68 \\
\hline & Female & $0.346 \pm 0.67$ & 0.100 & \\
\hline \multirow[t]{2}{*}{ Age N (\%) } & $\leq 65$ years & $0.230 \pm 0.48$ & 0.100 & 0.012 \\
\hline & $>65$ years & $0.639 \pm 1.44$ & 0.150 & \\
\hline \multirow[t]{2}{*}{ Diabetes status } & Yes & $0.179 \pm 0.17$ & 0.100 & 0.49 \\
\hline & No & $0.523 \pm 1.25$ & 0.100 & \\
\hline \multirow[t]{2}{*}{ Body mass index } & $\leq 25 \mathrm{~kg} / \mathrm{m}^{2}$ & $0.588 \pm 1.36$ & 0.170 & 0.009 \\
\hline & $>25 \mathrm{~kg} / \mathrm{m}^{2}$ & $0.249 \pm 0.58$ & 0.095 & \\
\hline \multirow[t]{2}{*}{ Cigarette smoking } & Ever & $0.303 \pm 0.51$ & 0.150 & 0.27 \\
\hline & Never & $0.692 \pm 1.71$ & 0.100 & \\
\hline
\end{tabular}

AhR, Aryl hydrocarbon receptor

\section{Statistical analysis}

The descriptive analysis was conducted from the case-control state using Chi-square statistics. The associations between the patients' characteristics and AhR expression were evaluated using Mann-Whitney $\mathrm{U}$ test. The hypothesis of normality was evaluated using the Shapiro-Wick test. The determinant of AhR was calculated from a simple linear regression with log-transform on AhR. Odds ratios (ORs) were calculated using unconditional logistic regression models with a $95 \%$ confidence interval (CLs) adjusted for sex, age (upper and lower compared with the age of 65 participants), body mass index (below or above the WHO limit point $\left(=25 \mathrm{~kg} / \mathrm{m}^{2}\right)$, diabetes status, and cigarette smoking. $P$ values of $<0.05$ were considered as statistically significant. These analyzes were performed using the STATA software, version 12.0 (Stata Corp., College Station, TX, USA).

\section{RESULTS}

\section{Clinical Characteristics of the study participants}

Clinical features of a total of 123 participants were studied for age, sex, body mass index (BMI), and history of diabetes and smoking. The mean age and BMI of all participants were $65 \pm 10$ years and $24.5 \pm 5.1 \mathrm{~kg} / \mathrm{m}^{2}$, respectively. $61(49.6 \%)$ of the patients were men. At enrollment in the study, $63(51.2 \%)$ participants were over 65 years old. Almost $24(37.5 \%)$ of the controls did not have a smoking history. This was 19 (32.2\%) in the patients group. Overall there were no statistical differences in the basic characteristics between the cases and the controls. The characteristics of the patients and healthy volunteers were presented in table 1 .

\section{Correlation analysis between the clinical features of all participants with AhR}

The association between AhR and characteristics of the participants is summarized in table 2 . As can clearly 
Table 3: Association between AhR and baseline characteristics due to the case-control group

\begin{tabular}{|c|c|c|c|c|c|c|c|c|}
\hline \multirow{3}{*}{ Characteristics } & & \multicolumn{6}{|c|}{$\operatorname{AhR}(\mathrm{ng} / \mathrm{mL})$} & \multirow{3}{*}{$P$ value } \\
\hline & & \multicolumn{3}{|c|}{ Case $(n=59)$} & \multicolumn{3}{|c|}{ Control $(n=64)$} & \\
\hline & & Mean \pm SD & Median & $P$ value & Mean \pm SD & Median & $P$ value & \\
\hline All participants & & $0.713 \pm 1.59$ & 0.280 & - & $0.371 \pm 1.23$ & 0.070 & - & 0.000 \\
\hline \multirow[t]{2}{*}{ Sex N (\%) } & Male & $0.713 \pm 1.59$ & 0.280 & \multirow[t]{2}{*}{0.010} & $0.371 \pm 1.23$ & 0.070 & \multirow[t]{2}{*}{0.171} & 0.000 \\
\hline & Female & $0.326 \pm 0.57$ & 0.100 & & $0.365 \pm 0.76$ & 0.095 & & 0.377 \\
\hline \multirow[t]{2}{*}{ Age N (\%) } & $\leq 65$ years & $0.329 \pm 0.68$ & 0.180 & \multirow[t]{2}{*}{0.228} & $0.143 \pm 0.17$ & 0.080 & \multirow[t]{2}{*}{0.384} & 0.001 \\
\hline & $>65$ years & $0.685 \pm 1.51$ & 0.260 & & $0.593 \pm 1.40$ & 0.085 & & 0.036 \\
\hline \multirow[t]{2}{*}{ Diabetes status } & Yes & $0.206 \pm 0.20$ & 0.135 & \multirow[t]{2}{*}{0.078} & $0.138 \pm 0.11$ & 0.085 & \multirow[t]{2}{*}{0.842} & 0.000 \\
\hline & No & $0.652 \pm 1.41$ & 0.260 & & $0.421 \pm 1.12$ & 0.080 & & 0.200 \\
\hline \multirow[t]{2}{*}{ Body mass index } & $\leq 25 \mathrm{~kg} / \mathrm{m}^{2}$ & $0.687 \pm 1.46$ & 0.190 & \multirow[t]{2}{*}{0.272} & $0.465 \pm 1.24$ & 0.090 & \multirow[t]{2}{*}{0.134} & 0.035 \\
\hline & $>25 \mathrm{~kg} / \mathrm{m}^{2}$ & $0.207 \pm 0.12$ & 0.250 & & $0.277 \pm 0.75$ & 0.070 & & 0.007 \\
\hline \multirow[t]{2}{*}{ Cigarette smoking } & Ever & $0.420 \pm 0.67$ & 0.260 & \multirow[t]{2}{*}{0.009} & $0.187 \pm 0.25$ & 0.075 & \multirow[t]{2}{*}{0.439} & 0.000 \\
\hline & Never & $0.719 \pm 1.88$ & 0.100 & & $0.670 \pm 1.60$ & 0.085 & & 0.614 \\
\hline
\end{tabular}

Table 4: Determinants of AhR with 95\% confidence interval (CI) from pancreatic cancer and corresponding control subjects using multivariate logistic regression

\begin{tabular}{lcc}
\hline Characteristics & Coefficient* $\mathbf{9 5 \%}$ CI) & P value \\
\hline Sex & & 0.657 \\
\hline$\quad$ Male / Female & $1.09(0.72-1.64)$ & 0.018 \\
\hline Age group & $1.61(1.08-2.38)$ & 0.004 \\
\hline$\quad>65 / \leq 65$ & $1.84(1.22-2.77)$ & 0.868 \\
\hline Body mass index & & \\
\hline$\leq 25 />25$ & $1.03(0.68-1.56)$ & 0.065 \\
\hline Smoking & & \\
\hline Ever / Never & $0.65(0.40-1.02)$ & \\
\hline Diabetes, N (\%) & & \\
\hline$\quad$ Yes / No & & \\
\hline *Exact value of coefficients was calculated & & \\
\hline
\end{tabular}

be seen from the table, the plasma level of AhR has a direct correlation with age $(p=0.012)$ and inverse association with BMI $(p=0.009)$. People over the age of 65 years had a significantly higher mean of AhR than the younger group $(0.230 \mathrm{vs} 0.639 \mathrm{ng} / \mathrm{mL})$. And the mean plasma level of AhR decreased in subjects with BMI above $25 \mathrm{~kg} / \mathrm{m}^{2}$ compared with those with less than 25 ( 0.249 vs 0.588$)$. There were no significant differences in AhR between male and female subjects and also never to ever smokers, however never smokers had higher level of AhR. Table 3 presents the association between the expression of AhR and the potential correlated factors between the cases and controls. The median of AhR among patients was $0.280 \mathrm{ng} / \mathrm{mL}$, which significantly differed from $0.07 \mathrm{ng} / \mathrm{mL}$ in the control group $(p<0.001)$. Fur- thermore, there were significant differences between AhR plasma level of the case and control groups, in respect to male sex $(p<0.001)$, age $\leq 65$ years $(p=0.001)$, diabetic status $(p<0.001)$, BMI categories $(p=0.035)$ and ever smoking $(p<0.001)$. We also observed significant differences between the level of AhR expression between male and female sex $(p=0.01)$ and ever and never smokers $(p=0.009)$ in the case group.

\section{Determinants of AhR level}

Table 4 shows the coefficients of the determinants derived from the linear regression for the plasma level of AhR from the patients with pancreatic cancer and corresponding control subjects. Subjects over 65 years of age and with a BMI of 25 or less had significant coefficients 
Table 5: Crude and adjusted ORs for pancreatic cancer and 95\% CI in relation to AhR by logistic regression analysis for several models

\begin{tabular}{llcc}
\hline Model & \multicolumn{1}{c}{ AhR } & Crude OR (95\% CI) & Adjusted* OR (95\% CI) \\
\hline 1 & Continuous scale & $1.13(0.80,1.59)$ & $1.15(0.81,1.65)$ \\
\hline 2 & Quartile scale & 1 & \\
\hline 1 & $4.43(1.47,13.35)$ & $4.39(1.41,13.61)$ \\
\hline & 2 & $8.28(2.68,25.30)$ & $8.39(2.64,26.65)$ \\
\hline 3 & 4 & $6.40(2.07,19.51)$ & $6.08(1.84,20.01)$ \\
\hline 4 & Linear trend of quartiles & $1.02(1.01,1.03)$ & $1.02(1.01,1.04)$ \\
\hline \multicolumn{5}{c}{ Dichotomous scale } & 1 & $3.40(1.55,7.45)$ \\
\hline
\end{tabular}

* Adjusted for age, sex, body mass index, smoking, and diabetes status.

on AhR level (1.61 IC 95\% 1.08-2.38), (1.84 IC 95\% 1.22-2.77), respectively. However, due to weight loss in patients with cancer, the significant coefficient may not be valid in this situation.

\section{Pancreatic cancer in association with plasma level of AhR}

Table 5 shows the crude and adjusted ORs and 95\% CIs for pancreatic cancer risk in relation to the levels of AhR in scales of continuous, quartile, and dichotomous. The adjusted ORs and 95\% CI for pancreatic cancer in relation to AhR levels in continues scale was 1.13 $(0.80,1.59)$. However there was a trend of higher median of AhR in patients with pancreatic cancer in conditional regression models. The risk of pancreatic cancer in quartile 2, 3, and 4 of AhR compared with quartile 1 was 4.43 (95\% Cl 1.47-13.35), 8.28 (95\% Cl 2.68-25.30), and 6.40 (95\% $\mathrm{Cl} 2.07-19.51)$, respectively, which were statistically significant. The association persisted when adjusted for the covariates that are shown in the table footnotes. Finally, considering the AhR as a dichotomous scale in the model, this significant relationship was still well kept with pancreatic cancer $(3.44,95 \% \mathrm{CI}$ 1.62-7.19).

\section{DISCUSSION}

Some studies have indicated the underlying mechanisms caused by AhR in the development of cancer and the association between irregular expression of $\mathrm{AhR}$ and tumors. ${ }^{20} \mathrm{AhR}$ is produced mainly in different adult tissues, especially in the liver, kidneys, lungs, and heart, ${ }^{10,12,13-15}$ however the presence of AhR in the circulatory system in patents with pancreatic cancer has not been evaluated.

Our finding revealed the increased level of AhR in patients with pancreatic cancer compared with healthy conditions. Meanwhile, an increase in plasma AhR occurred in participants over the age of 65 and BMI below $25 \mathrm{~kg} / \mathrm{m}^{2}$. Subsequently, the age of 65 and the BMI of less than 25 were significant determinants of AhR. These results are consistent with previous studies that examined the association between age and AhR. The study by Eckers and colleagues revealed a positive association between AhR expression of red blood cells and vascular rigidity as an index of vascular aging in healthy human subjects. ${ }^{13}$ Age is a crucial cause of the development of a series of cancers and probably increases the risk of pancreatic cancer in over 60 years. ${ }^{1,21}$ However, very few data concerning AhR and BMI are available. The methylation of the AhR repressor (AHRR) gene from cord blood was positively associated with maternal BMI. ${ }^{22}$ The AHRR protein inhibits the AhR function by stopping the AHR/ ARNT complex. Pancreatic tumors tend to be diagnosed at a later stage when patients are progressive in association with weight loss. Thus a significant relationship between the AhR plasma level and the BMI below 25 in this study is interfering with the patients' weight loss. Koliopanos and co-workers showed high levels of AhR human expression in pancreatic cancer tissues and suggested the potential role of AhR modulators as novel chemotherapeutic agents. ${ }^{14}$ Furthermore, it has been shown that patients with high AhR expression may be more susceptible to active therapy with AhR. ${ }^{23}$ 
The possible reasons for elevated plasma levels of $\mathrm{AhR}$ in patients with pancreatic cancer can be explained by different approaches that could increase our knowledge on the role of AhR in tumorigenesis. P450 enzymes that have been shown to be stimulated due to environmental dioxins and dioxin-like compounds, are able to induce oxidative stress and the production of reactive oxygen species (ROS). ${ }^{24}$ Furthermore, oxidative stress contributes potentially to the dioxin-induced mitochondrial toxicity, ${ }^{11}$ DNA damage and lipid peroxidation. Alternatively, it is known that AhR activation is important in the promotion of the tumor that metabolizes xenobiotics and converts inactive carcinogens into active genotoxins. Furthermore, the activation of AhR by endogenous ligands such as kynurenine inhibits autoimmunity and immune responses to pathogens in tolerance system. Kynurenine is produced in tryptophan dioxygenase (TDO) and indoleamine 2,3-dioxygenase (IDO) pathways and plays a role in the development of regulatory $\mathrm{T}$ (Treg) cells. However, a large amount of AhR kynurenine ligands are generated by the tumor cells to their own advantage in immune tolerance to cancer to facilitate tumor progression. A positive correlation between high TDO expression and the CYP1B1 that is regulated by AhR has been reported in human cancer. ${ }^{25}$

In conclusion, this study revealed significant associations between plasma levels of AhR and pancreatic cancer, which suggest that AhR could be an effective target in the therapeutic strategies of pancreatic tumors through AhR antagonists.

\section{ACKNOWLEDGEMENTS}

Authors of this article take this chance to appreciate the patients who participated in this study.

\section{Authors and Contributions}

All authors participated in the conception of the work, experimental and clinical analysis, and interpretation of data and writing of this paper. They have seen and approved the final manuscript and come across the criteria for authorship.

\section{ETHICAL APPROVAL}

There is nothing to be declared.

\section{CONFLICT OF INTEREST}

The authors declare no conflict of interest related to this work.

\section{REFERENCES}

1. Shakeri R, Kamangar F, Mohamadnejad M, Tabrizi R, Zamani F, Mohamadkhani A, et al. Opium use, cigarette smoking, and alcohol consumption in relation to pancreatic cancer. Medicine (Baltimore) 2016;95:e3922. doi:10.1097/MD.0000000000003922.

2. Schneider G, Siveke JT, Eckel F, Schmid RM. Pancreatic cancer: basic and clinical aspects. Gastroenterology 2005;128:1606-25. doi:10.1053/j.gastro.2005.04.001.

3. Bandyopadhyay S, Mitra R, Maulik U, Zhang MQ. Development of the human cancer microRNA network. Silence 2010;1:6. doi:10.1186/1758-907X-1-6.

4. Mohamadkhani A, Akbari MR, Ghanbari R, Naderi E, Rezanejad-Asl P, Pourshams A. Direct Sequencing of Cyclooxygenase-2 (COX-2) Revealed an Intronic Variant rs201231411 in Iranian Patients with Pancreatic Cancer. Middle East J Dig Dis 2015;7:14-8.

5. Oesch-Bartlomowicz B, Huelster A, Wiss O, AntoniouLipfert P, Dietrich C, Arand M, et al. Aryl hydrocarbon receptor activation by cAMP vs. dioxin: divergent signaling pathways. Proc Natl Acad Sci U S A 2005;102:921823. doi:10.1073/pnas.0503488102.

6. Jaeger C, Tischkau SA. Role of Aryl Hydrocarbon Receptor in Circadian Clock Disruption and Metabolic Dysfunction. Environ Health Insights 2016;10:133-41. doi:10.4137/EHI.S38343.

7. Kewley RJ, Whitelaw ML, Chapman-Smith A. The mammalian basic helix-loop-helix/PAS family of transcriptional regulators. Int J Biochem Cell Biol 2004;36:189204. doi:10.1016/S1357-2725(03)00211-5.

8. Gu YZ, Hogenesch JB, Bradfield CA. The PAS superfamily: sensors of environmental and developmental signals. Annu Rev Pharmacol Toxicol 2000;40:519-561. doi:10.1146/annurev.pharmtox.40.1.519.

9. Quintana FJ, Murugaiyan G, Farez MF, Mitsdoerffer M, Tukpah AM, Burns EJ, et al. An endogenous aryl hydrocarbon receptor ligand acts on dendritic cells and T cells to suppress experimental autoimmune encephalomyelitis. Proc Natl Acad Sci U S A 2010;107:20768-73. doi: 10.1073/pnas. 1009201107.

10. Xie F, Ding X, Zhang QY. An update on the role of intestinal cytochrome P450 enzymes in drug disposition. Acta Pharm Sin B 2016;6:374-83. doi:10.1016/j. apsb.2016.07.012.

11. Forgacs AL, Burgoon LD, Lynn SG, LaPres JJ, Zacharewski T. Effects of TCDD on the expression of nuclear encoded mitochondrial genes. Toxicol Appl Pharmacol 2010;246:58-65. doi:10.1016/j.taap.2010.04.006.

12. Moossavi S, Besharat S, Sharafkhah M, Ghanbari R, Sharifi A, Rezanejad P, et al. Inverse Association of Plas- 
ma Level of Glutathione Peroxidase with Liver Fibrosis in Chronic Hepatitis B: Potential Role of Iron. Middle East J Dig Dis 2016;8:122-30. doi:10.15171/mejdd.2016.17.

13. Eckers A, Jakob S, Heiss C, Haarmann-Stemmann T, Goy C, Brinkmann V, et al. The aryl hydrocarbon receptor promotes aging phenotypes across species. Sci Rep 2016;6:19618. doi:10.1038/srep19618.

14. Koliopanos A, Kleeff J, Xiao Y, Safe S, Zimmermann A, Buchler MW, et al. Increased arylhydrocarbon receptor expression offers a potential therapeutic target for pancreatic cancer. Oncogene 2002;21:6059-70. doi:10.1038/sj.onc.1205633.

15. Tran C, Richmond O, Aaron L, Powell JB. Inhibition of constitutive aryl hydrocarbon receptor (AhR) signaling attenuates androgen independent signaling and growth in (C4-2) prostate cancer cells. Biochem Pharmacol 2013;85:753-62. doi:10.1016/j.bcp.2012.12.010.

16. Zakeri S, Amiri N, Pirahmadi S, Dinparast Djadid N. Genetic variability of CYP2B6 polymorphisms in southeast Iranian population: implications for malaria and HIV/ AIDS treatment. Arch Iran Med 2014;17:685-91. doi: 0141710/AIM.009.

17. Youns M, Efferth T, Hoheisel JD. Transcript profiling identifies novel key players mediating the growth inhibitory effect of NS-398 on human pancreatic cancer cells. Eur J Pharmacol 2011;650:170-7. doi:10.1016/j. ejphar.2010.10.026.

18. Farrokhzad S, Nedjat S, Kamangar F, Kamali M, Malekzadeh R, Pourshams A. Validity and reliability of a questionnaire designed to assess risk factors of pancreatic cancer in Iran. Arch Iran Med 2014;17:102-5. doi: 014172/AIM.003.

19. Mohamadkhani A, Poustchi H. Repository of Human Blood Derivative Biospecimens in Biobank: Technical Implications. Middle East J Dig Dis 2015;7:61-8.

20. Safe S, Lee SO, Jin UH. Role of the aryl hydrocarbon receptor in carcinogenesis and potential as a drug target. Toxicol Sci 2013;135:1-16. doi:10.1093/toxsci/kft128.

21. Higuera O, Ghanem I, Nasimi R, Prieto I, Koren L, Feliu J. Management of pancreatic cancer in the elderly. World $J$ Gastroenterol 2016;22:764-75. doi:10.3748/wjg.v22.i2.764.

22. Burris HH, Baccarelli AA, Byun HM, Cantoral A, Just AC, Pantic I, et al. Offspring DNA methylation of the aryl-hydrocarbon receptor repressor gene is associated with maternal BMI, gestational age, and birth weight. Epigenetics 2015;10:913-21. doi:10.1080/15592294.20 15.1078963.

23. Jin UH, Kim SB, Safe S. Omeprazole Inhibits Pancreatic Cancer Cell Invasion through a Nongenomic Aryl Hydrocarbon Receptor Pathway. Chem Res Toxicol 2015;28:907-18. doi:10.1021/tx5005198.

24. Kim JT, Kim SS, Jun DW, Hwang YH, Park WH, Pak YK, et al. Serum arylhydrocarbon receptor transactivating activity is elevated in type 2 diabetic patients with diabetic nephropathy. J Diabetes Investig 2013;4:483-91. doi:10.1111/jdi.12081.
25. Murray IA, Patterson AD, Perdew GH. Aryl hydrocarbon receptor ligands in cancer: friend and foe. Nat Rev Cancer 2014;14:801-14. doi:10.1038/nrc3846. 